\title{
Opinión de médicos peruanos sobre la aplicación actual de terapias con células madre*
}

\section{Peruvian doctor's opinion on the application of stem cell therapies}

Correspondencia Jaime Millás Mur jmillasmur@gmail.com

Recibido: 10/02/2017

Arbitrado por pares

Aprobado: 17/05/2017

Citar como: Millás-Mur J. Opinión de médicos peruanos sobre la aplicación actual de terapias con células madre. Acta Med Peru. 2017;34(2):82-9
Jaime Millás-Mur ${ }^{1, a}$

1 Facultad de Medicina, Universidad de Piura. Lima, Perú.

a Licenciado en Biología y Doctor en Bioética

* Este trabajo forma parte de la tesis doctoral en Bioética sustentada en la Universidad Católica de Valencia (España) el 15 de diciembre 2016 por el autor de este artículo. En ella se efectúa además un análisis de los aspectos biomédicos y bioéticos de estas terapias y una revisión de las normas sobre ensayos clínicos en seres humanos.

\section{RESUMEN}

Objetivo: Conocer la opinión de un grupo de médicos peruanos sobre las características positivas y negativas acerca de los tratamientos con células madre que se realizan en clínicas del Perú y de otros países de Latinoamérica. La población está circunscrita a los médicos asistenciales que trabajan en diferentes hospitales, cualquiera que sea su especialidad. Materiales y métodos: Estudio descriptivo transversal. Se aplicó una encuesta a una muestra no probabilística de médicos peruanos. El cuestionario se construyó en base a las recomendaciones de la International Society for Stem Cell Research (ISSCR) en su Guidelines for the Clinical Translation of Stem Cells (Guía para la Traslación Clínica de las Células Madre). Resultados: Según nuestros resultados, la opinión de un grupo de médicos peruanos es que, en el Perú y Latinoamérica, se oferta la terapia con células madre para un gran número de dolencias, en primer lugar y con un importante porcentaje $(30,9 \%)$ para las enfermedades neurodegenerativas. En la sección del cuestionario aplicado sobre estudios preclínicos, es importante el porcentaje en el que pocas veces o nunca se elimina el riesgo de producir tumores (38\%). Respecto a la sección investigación clínica, llama la atención que en un $42 \%$ apenas o nunca tienen identificados los riesgos ni claros posibles beneficios de estas terapias. Conclusiones: Los médicos entrevistados consideran que se estaría ofertando terapias con células madre para tratar enfermedades muy diversas, entre las que destacan las neurodegenerativas, que en la actualidad son incurables y los posibles tratamientos están a nivel de ensayos clínicos, lo que no sería ético.

Palabras clave: Células madre; Tratamiento basado en trasplante de células y tejidos; Investigación en medicina traslacional (fuente: DeCS BIREME). 


\begin{abstract}
Objective: To know the opinion of a group of Peruvian physicians about the positive and negative characteristics of stem cell therapies performed in clinics in Peru and other Latin American countries. The population is circumscribed to attending physicians working in different hospitals, whatever their specialty is. Materials and methods: This is a cross-sectional descriptive study. A survey was applied to a non-probabilistic sample of Peruvian physicians. The questionnaire was built based on the recommendations of the International Society for Stem Cell Research (ISSCR) set in its Guidelines for the Clinical Translation of Stem Cells. Results: According to our findings, the opinion of a group of Peruvian doctors is that in Peru and Latin America, stem cell therapy is offered for a large number of diseases, with a significant frequency (30.9\%) for neurodegenerative diseases. In the section of the questionnaire with respect to preclinical studies, it is important to point out the percentage in which the risk of producing tumors (38\%) is seldom or never eliminated. Regarding the clinical research section, it is noteworthy that in $42 \%$ the risks or clear potential benefits of these therapies have barely or never been identified. Conclusions: The interviewed physicians believe that stem cell therapies are offered for treating a wide variety of diseases, particularly neurodegenerative diseases, which are currently non-curable, and for which possible options of therapy are at the level of clinical trials, so it would not be ethical to offer stem cell therapies for such conditions.
\end{abstract}

Keywords: Stem cells; Cell- and tissue-based therapy; Translational medical research (source: MeSH NLM).

\section{INTRODUCCIÓN}

Las células madre o células troncales (en inglés: stem cells) son aquellas células que por su plasticidad y potencialidad de diferenciación, así como por su capacidad generativa, dan lugar tanto a células similares -que conservan las mismas capacidades- como a otro tipo de células ya diferenciadas en un tejido específico ${ }^{[1]}$. A partir de las células madre se ha logrado obtener en el laboratorio diversos tipos de células que van desde células sanguíneas hasta neuronas, lo que ha llevado a plantear la posibilidad de que se podrían curar con ellas diversas enfermedades.

Se han tenido diversos resultados con la aplicación de la terapia celular: el alivio de algunas patologías de naturaleza hematológica, inmunitaria y tumoral ${ }^{[2]}$; la regeneración de la piel con células madre epidérmicas ${ }^{[3]}$; el tratamiento de problemas articulares en base a condrocitos autólogos ${ }^{[4]}$; el trasplante de células madre del limbo corneal para reparar úlceras ${ }^{[5]}$; terapia con células madre mesenquimales para tratar la enfermedad de injerto contra huésped en niños ${ }^{[6]}$; terapia con fibroblastos autólogos para la reducción de líneas de expresión en el rostro [7]; terapia con células dendríticas obtenidas de monocitos para inmunoterapia autóloga contra el cáncer de próstata-resistente a tratamiento hormonal- asintomático o mínimamente invasivo ${ }^{[8]}$. Existen también tratamientos experimentales que están en proceso de ensayo clínico, para la solución de problemas como el infarto del miocardio ${ }^{[9]}$ y fístulas perianales ${ }^{[10]}$. En otros casos, como las enfermedades neurológicas, el avance es todavía muy discreto ${ }^{[1]}$.

Aunque hay un notable progreso en la investigación, las expectativas son mucho mayores que la aplicación clínica de estas terapias ${ }^{[12]}$. Además, al parecer se vienen ofertando terapias con células madre sin las garantías de seguridad y eficacia necesarias, incluso cuando las células provienen del propio paciente ${ }^{[13,14]}$.
Es significativo el avance en investigación con células madre adultas a nivel mundial. La página web de los Institutos Nacionales de Salud de los Estados Unidos registra en la actualidad 5716 ensayos clínicos con células madre adultas, de los que 676 se encuentran en fases III y IV. En cambio sólo figuran 46 ensayos con células de origen embrionario ${ }^{[15]}$.

El objetivo de nuestro estudio es conocer la opinión de un grupo de profesionales de la medicina sobre las características de los tratamientos con células madre que se realizan en clínicas del Perú y de otros países de Latinoamérica. La hipótesis de trabajo es que, en opinión de médicos peruanos, tanto en Perú como en Latinoamérica existen pacientes que reciben terapia celular sin las debidas medidas de seguridad y sin la comprobación, por medio de procedimientos preclínicos y ensayos clínicos, de la eficacia del procedimiento.

\section{MATERIALES Y MÉTODOS}

\section{Diseño del estudio}

Estudio descriptivo transversal. Se aplicó un cuestionario estructurado a un grupo de médicos peruanos con el fin de recabar su opinión sobre las terapias que ofrecen diversas clínicas en Latinoamérica. Dicho cuestionario fue preparado en base a la Guidelines for the Clinical Translation of Stem Cells elaborada por la International Society for Stem Cell Research (ISSCR) ${ }^{[16]}$ Esta guía se desarrolla de acuerdo a tópicos científicos, clínicos, éticos, reguladores y sociales que deben tenerse en cuenta para que la investigación con células madre sea trasladada de manera responsable a aplicaciones clínicas para el tratamiento de los pacientes. Contiene 40 recomendaciones, las cuales fueron tomadas en cuenta para elaborar un cuestionario de 57 preguntas, divididas en las secciones: procesamiento y producción celular, estudios preclínicos, investigación clínica, innovaciones médicas con células madre y consideraciones sobre justicia social. 
Tabla 1. Datos generales de los médicos entrevistados.

\begin{tabular}{|c|c|}
\hline Variable & $\mathrm{n}(\%)$ \\
\hline \multicolumn{2}{|l|}{ Edad (años) } \\
\hline Menor de 30 & $185(39,2)$ \\
\hline 30 a 39 & $158(33,5)$ \\
\hline 40 a más & $118(25,0)$ \\
\hline Sin dato & $11(2,3)$ \\
\hline \multicolumn{2}{|l|}{ Sexo } \\
\hline Masculino & $287(60,8)$ \\
\hline Femenino & $185(39,2)$ \\
\hline \multicolumn{2}{|l|}{ Lugar de residencia } \\
\hline Lima & $441(93,4)$ \\
\hline Otras ciudades & $26(5,5)$ \\
\hline Sin dato & $5(1,1)$ \\
\hline \multicolumn{2}{|l|}{ Labor social los últimos tres años } \\
\hline Sí & $178(37,7)$ \\
\hline No & $289(61,2)$ \\
\hline Sin dato & $5(1,1)$ \\
\hline \multicolumn{2}{|l|}{ Especialidad } \\
\hline Médico general & $197(41,7)$ \\
\hline Clínica & $162(34,3)$ \\
\hline Quirúrgica & $92(19,7)$ \\
\hline Laboratorio & $16(3,4)$ \\
\hline Otra & $1(0,2)$ \\
\hline Sin dato & $4(0,9)$ \\
\hline \multicolumn{2}{|l|}{ Años de experiencia } \\
\hline Menos de 5 & $246(52,1)$ \\
\hline 5 a 14 & $153(32,4)$ \\
\hline 15 a más & $71(15,0)$ \\
\hline Sin dato & $2(0,4)$ \\
\hline \multicolumn{2}{|c|}{ Universidad de procedencia (pregrado) } \\
\hline UNMSM & $119(25,2)$ \\
\hline USMP & $101(21,4)$ \\
\hline UPCH & $52(11,0)$ \\
\hline Otras universidades nacionales & $192(40,7)$ \\
\hline Universidad extranjera & $2(0,4)$ \\
\hline Sin dato & $6(1,3)$ \\
\hline
\end{tabular}

UNMSM: Universidad Nacional Mayor de San Marcos; USMP: Universidad San Martín de Porres; UPCH: Universidad Peruana Cayetano Heredia

\section{Población de estudio}

La selección de los médicos fue por conveniencia. La aplicación del cuestionario fue presencial en el $94 \%$ de los casos y el resto por vía electrónica (aplicación de encuestas de Google Drive). La población estuvo circunscrita a los médicos asistenciales, cualquiera que sea su especialidad. El contacto se realizó través de seis médicos entrenados para la recolección de datos quienes invitaron a los potenciales participantes. La encuesta virtual se aplicó a un pequeño número de médicos con los que no era posible hacerlo de forma presencial.

Los médicos participantes provinieron de diferentes hospitales de la ciudad de Lima: Hospital Nacional Edgardo Rebagliati Martins, Hospital Nacional Arzobispo Loayza, Hospital Nacional
Daniel Alcides Carrión, Hospital de San Juan de Lurigancho, Hospital Nacional Dos de Mayo y Hospital Nacional Madre Niño "San Bartolomé"; además de médicos de las ciudades de Piura y Arequipa, y médicos residentes que se encontraban rotando en el exterior del país. El periodo de recolección de datos se realizó en dos periodos: el primero para la vía electrónica entre diciembre del año 2013 y setiembre del 2014; el segundo para las entrevistas presenciales entre octubre de 2014 y abril de 2016.

\section{Variables}

El instrumento de recolección de datos se dividió en seis secciones: datos generales y antecedentes académicos del médico: edad, sexo, lugar de residencia, realizar labor social, especialidad (medicina general, clínica, quirúrgica, laboratorio), años de experiencia, universidad de procedencia en pregrado, tener estudios de posgrado, haber participado en congresos en los últimos 3 años, tener pacientes que podrían beneficiarse de la terapia, conocimiento de tipos de clínicas, políticas y regulaciones, tipos de terapia y comités de ética relacionados a las terapias de células madre (14 preguntas); procesamiento y producción celular: consentimiento informado, análisis de enfermedades, marcadores de identificación y potencia, riesgo transferencia de patógenos, estándares de referencia, sistemas de calidad, normativa (ocho preguntas); estudios preclínicos: modelos animales, protocolo $3 R$ s, bioseguridad, evaluación en primates, supervisión veterinaria, descarte de toxicidad, riesgo de tumores, inmunosupresores (ocho preguntas); investigación clínica: investigación compartida, cooperación con otros centros, análisis de riesgos, claridad al tratar de beneficios, conflicto de interés, monitoreo de las personas, plan de información de efectos adversos, compensación por daños, cobertura de seguro, revisores independientes, identificación de riesgos y beneficios, selección de sujetos, terapias ya existentes, ventajas del uso de células madre, justificación del riesgo, libertad de acceso, beneficio para participantes, consentimiento informado, monitoreo de datos, garantía de seguridad para participantes, datos socio-culturales, publicación de datos (24 preguntas); innovaciones médicas con células madre: providencias para la aplicación de estas terapias (una pregunta) y justicia social: oferta de terapias y nivel económico, favorecimiento del beneficio social (dos preguntas). El cuestionario fue validado mediante juicio de expertos, quienes evaluaron el contenido, los criterios y la construcción del mismo.

\section{Análisis de datos}

En el programa Google Drive se digitaron las respuestas de los cuestionarios aplicados de manera presencial, obteniéndose una base de datos que fue exportada a Microsoft Excel donde, por medio del módulo de tablas dinámicas, se obtuvieron las frecuencias de los valores para las variables analizadas. Así mismo, se generaron gráficos de barras apiladas para representar las frecuencias relativas de las secciones procesamiento y producción celular, estudios preclínicos e investigación clínica.

Como parte del procedimiento de recolección de datos se solicitó el consentimiento de los médicos para su participación en la investigación, siendo el cuestionario anónimo y sin ningún tipo de identificador. 


\section{RESULTADOS}

Se completaron 472 cuestionarios. La mayoría de médicos entrevistados tenían entre 25 y 34 años. El 60,8\% fueron varones. La gran mayoría vivía en Lima (93,4\%). Categorizados por especialidad, la mayoría de entrevistados fueron médicos generales $(41,7 \%)$ y clínicos (34,3\%). El 52,1\% tenía menos de cinco años de experiencia. Respecto a la universidad de procedencia, destacan la Universidad Nacional Mayor de San Marcos (25,2\%), la Universidad San Martín de Porras con el $(21,4 \%)$ y la Universidad Peruana Cayetano Heredia $(11,0 \%)$ (Tabla 1).

El 39,6\% realizó estudios de posgrado. En el caso de asistencia a congresos en los últimos tres años, el 52,7\% indicó que no, el $46,2 \%$ respondió afirmativamente y el $1,1 \%$ no respondió.

El 54,2\% de los entrevistados considera que, en Latinoamérica, las clínicas que ofertan terapia con células madre son privadas. El 10,4\% piensa que estas clínicas no aceptan o desconocen políticas regulatorias y el $31,6 \%$ que tienen políticas diferentes a la de la ISSCR. La mayoría de los médicos entrevistados consideraban que, en Latinoamérica, se oferta la terapia con células madre para un gran número de dolencias, siendo la más frecuente el grupo de las enfermedades neurodegenerativas $(30,9 \%)$. El 24,8\% considera que no hay un Comité de Ética de Investigación en estas clínicas (Tabla 2).

Respecto al procesamiento y producción celular, los médicos perciben que en el $24 \%$ de los casos se firma el consentimiento informado siempre o casi siempre y en el $25 \%$ se hacen análisis sobre posibles enfermedades. En cambio, el uso en todos los casos de la normativa establecida baja al 7\%. En cuanto al desarrollo de sistemas de calidad y el trabajo con organismos reguladores, siempre o casi siempre, el resultado es el 27 y el $28 \%$, respectivamente (Figura 1 ).

El $38 \%$ consideró que los estudios preclínicos respecto a terapia de células madre eliminan pocas veces o nunca el riesgo de producir tumores (Figura 2).

En el caso de la investigación clínica, los médicos opinaron que el $42 \%$ identificaba poco o nunca los riesgos ni tenía claro los posibles beneficios de estas terapias. El $39 \%$ de los casos preveían casi nunca o nunca otorgar una compensación por posibles daños. El 31\% seleccionaba pocas veces o nunca a los sujetos que participarían en su estudio. Además, el 30\% de los participantes no publicaban sus trabajos en revistas científicas antes de darlos a conocer a través de medios de comunicación. (Figura 3).

Al explorar las opiniones sobre innovaciones médicas con células madre, el resultado indicó que el 32,6\% opinaba que debía aprobarse un plan por expertos. En los otros ítems el porcentaje es menor: entre 16,3 y $24,2 \%$. En cuanto al beneficio social que proporciona la colaboración entre investigadores, el 29,9\% afirmaba que era poco o nada.
Tabla 2. Percepción acerca de temas generales sobre las terapias con células madre por parte de los médicos entrevistados.

\begin{tabular}{|c|c|}
\hline Variable & n (\%) \\
\hline \multicolumn{2}{|l|}{ El médico entrevistado: } \\
\hline \multicolumn{2}{|c|}{$\begin{array}{l}\text { Tiene un paciente para quien la terapia con } \\
\text { células madre es una opción }\end{array}$} \\
\hline Sí & $67(14,2)$ \\
\hline No & $328(69,5)$ \\
\hline No sabe, no opina & $69(14,6)$ \\
\hline Sin dato & $8(1,7)$ \\
\hline \multicolumn{2}{|c|}{$\begin{array}{l}\text { Considera que, en Latinoamérica, las clínicas } \\
\text { que ofrecen terapia de células madre son } \\
\text { en su mayoría: }\end{array}$} \\
\hline Privadas & $256(54,2)$ \\
\hline Académicas & $55(11,6)$ \\
\hline Gubernamentales & $54(11,4)$ \\
\hline Otro & $1(0,2)$ \\
\hline No sabe, no opina & $102(21,6)$ \\
\hline Sin dato & $4(0,8)$ \\
\hline \multicolumn{2}{|c|}{$\begin{array}{l}\text { Considera que estas clínicas que ofrecen terapia } \\
\text { de células madre conocen y aceptan la guía } \\
\text { ISSCR y/u otras políticas y regulaciones: }\end{array}$} \\
\hline Guía ISSCR & $140(29,6)$ \\
\hline Otras políticas y regulaciones & $149(31,6)$ \\
\hline $\begin{array}{l}\text { No conocen o no aceptan políticas y } \\
\text { regulaciones }\end{array}$ & $49(10,4)$ \\
\hline No sabe, no opina & $133(28,2)$ \\
\hline Sin dato & $1(0,2)$ \\
\hline \multicolumn{2}{|c|}{$\begin{array}{l}\text { Considera que las clínicas en Latinoamérica } \\
\text { ofertan terapias que usan células madre } \\
\text { para tratar: }\end{array}$} \\
\hline Patologías neurodegenerativas & $146(30,9)$ \\
\hline Enfermedades hematológicas & $141(29,9)$ \\
\hline Cirugía plástica y reconstructiva & $139(29,4)$ \\
\hline Patologías cardiovasculares & $133(28,2)$ \\
\hline Enfermedades autoinmunes & $106(22,5)$ \\
\hline Cirugía ortopédica y traumatológica & $99(21,0)$ \\
\hline Regeneración hepática & $67(14,2)$ \\
\hline En oftalmología & $48(10,2)$ \\
\hline Otros & $7(1,5)$ \\
\hline No sabe, no opina & $77(16,3)$ \\
\hline \multicolumn{2}{|c|}{$\begin{array}{l}\text { Considera que hay un comité de ética de } \\
\text { investigación que revisa el trabajo de las clínicas } \\
\text { que ofrecen terapia de células madre: }\end{array}$} \\
\hline Sí & $192(40,7)$ \\
\hline No & $117(24,8)$ \\
\hline No sabe, no opina & $162(34,3)$ \\
\hline Sin dato & $1(0,2)$ \\
\hline
\end{tabular}

ISSCR: International Society for Stem Cell Research

\section{DISCUSIÓN}

Un hallazgo relevante del presente estudio es que más del $10 \%$ de médicos entrevistados sostuvo que las clínicas en donde se desarrollan prácticas con células madre, en su mayoría del sector privado, no conocían o no aceptaban políticas o regulaciones, lo que hace pensar al autor que habría faltas éticas en esta práctica. 


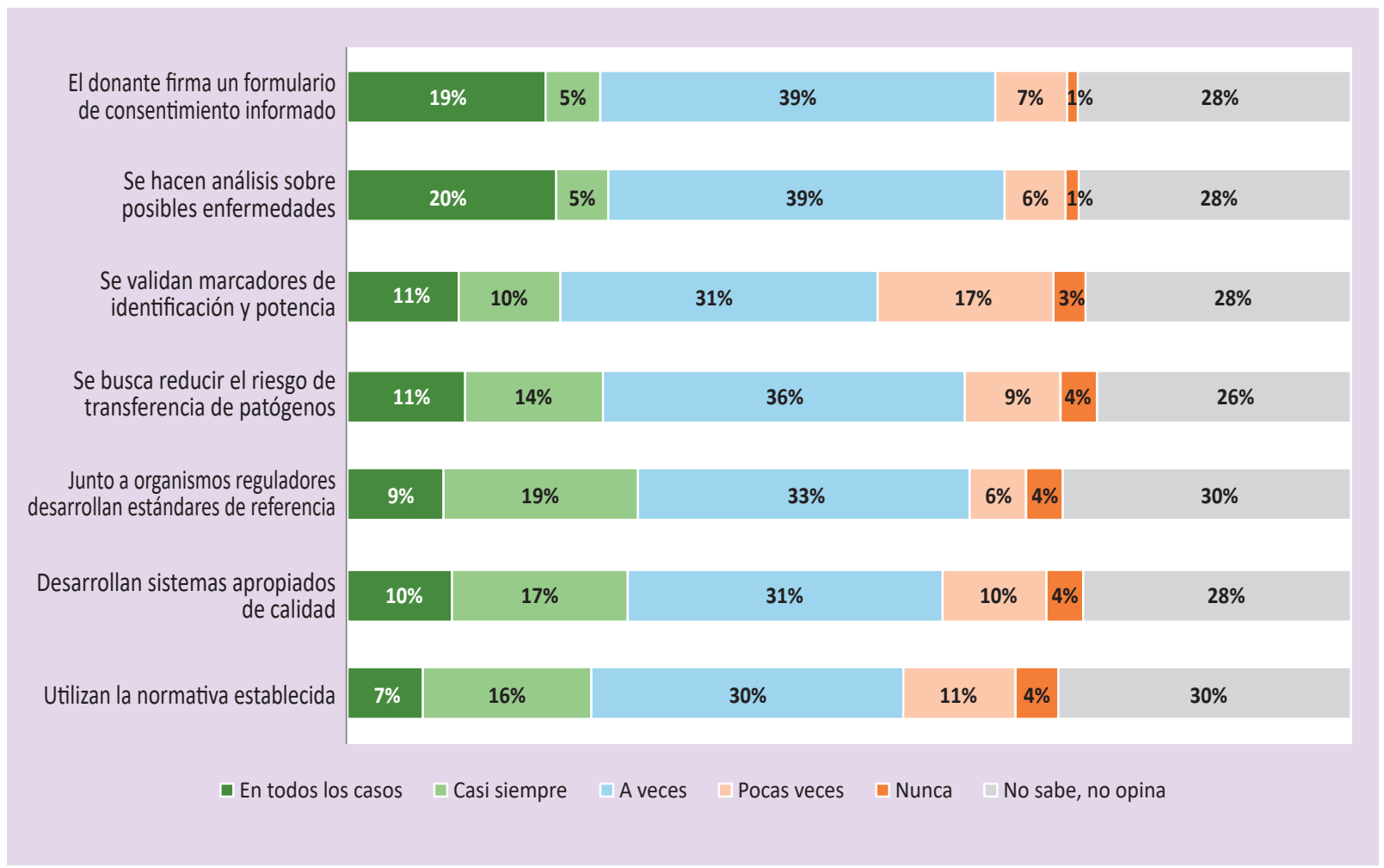

Figura 1. Percepción sobre procesamiento y producción celular por parte de los médicos entrevistados.

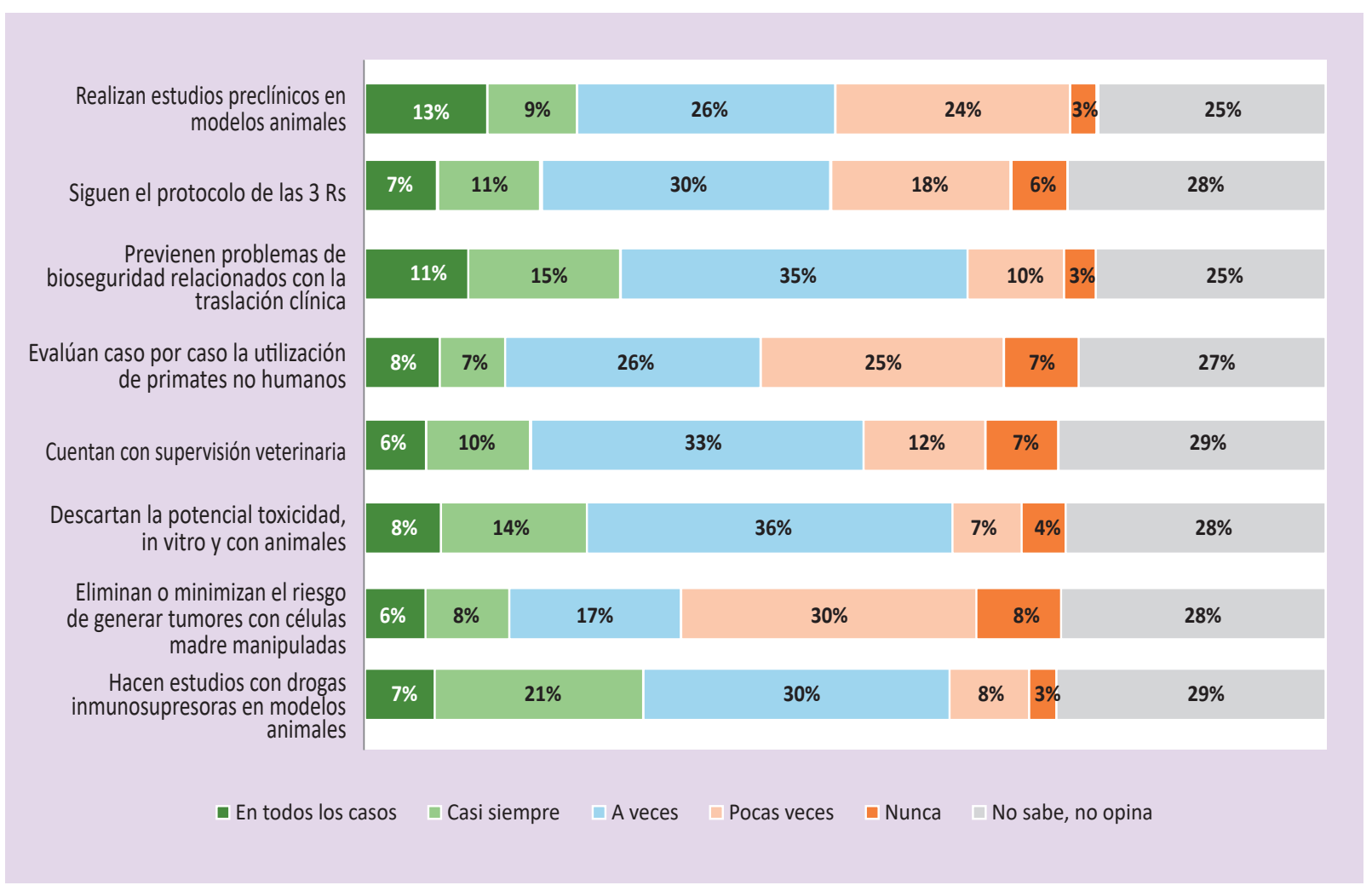

Figura 2. Percepción sobre estudios preclínicos en células madres por parte de los médicos entrevistados. 


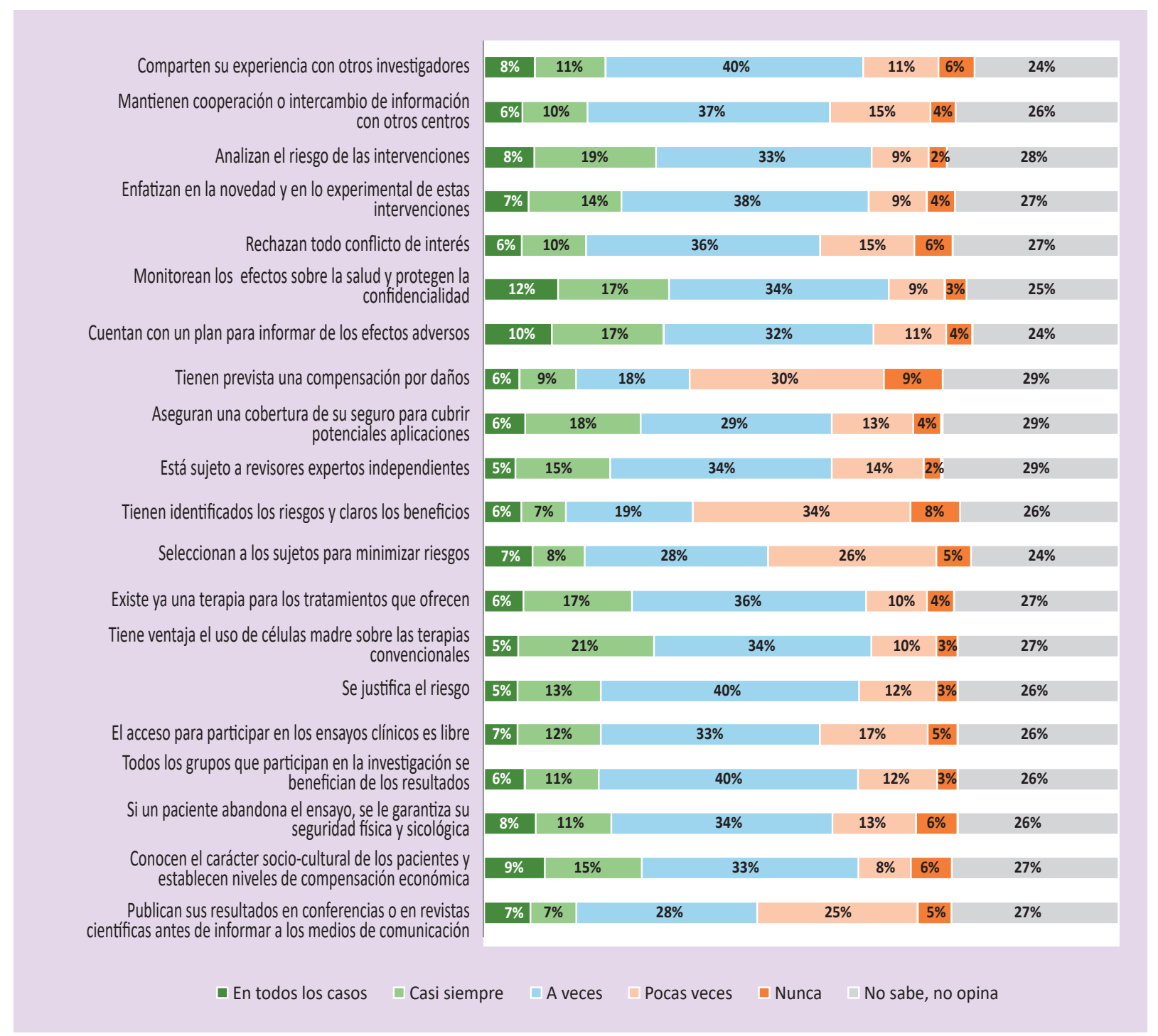

Figura 3. Percepción, por parte de los médicos entrevistados, sobre la investigación clínica con células madre.

Cuando se indagó sobre el procesamiento y producción celular, un grupo no despreciable (7\%) consideró que no siempre se actúa de acuerdo a la normativa establecida, lo que podríamos calificar de grave irregularidad ${ }^{[17]}$. Así mismo, en cuanto a los estudios preclínicos, el $38 \%$ opinó que nunca o pocas veces se eliminaba por completo el riesgo de desarrollar tumores luego del uso de terapia con células madre, lo que indicaría que los entrevistados consideran que se estaría poniendo en riesgo la vida de las personas que recibirán este tipo de terapias ${ }^{[18]}$. Y esto a pesar de que en el Perú y en Latinoamérica en general se usan sólo células madre adultas y no células madre embrionarias o pluripotenciales inducidas que son las tienen mayor riesgo de producir tumores ${ }^{[19]}$. Llama también la atención que sólo se señalen algunos ítems de las innovaciones médicas con células madre, y en proporciones relativamente bajas cuando en realidad todos deberían ser requeridos para aplicar terapias con células madre no comprobadas ${ }^{[20]}$.

Sobre la investigación clínica con células madre, que el $42 \%$ considere que no se tienen nunca o casi nunca identificados los riesgos ni claros los posibles beneficios, sugiere que se podría estar actuando de manera inadecuada en gran número de casos $^{[21]}$. Esto va unido a la falta de una posible compensación por daños que, en opinión de los médicos entrevistados, no se prevé nunca o casi nunca (39\%), lo que también sería injusto. Además, que casi un tercio de los participantes no seleccione a los sujetos de estudio podría hacer que los riesgos para algunos participantes sean aún mayores de lo inicialmente previsto, lo que agravaría el grado de responsabilidad a la hora de probar estos tratamientos. El que se considere que pocas veces o nunca se publiquen los resultados, ya sea positivos o negativos, en revistas científicas, en el $30 \%$ de los casos, llevaría a pensar que no habría garantía de un trabajo serio y, por tanto, de que los tratamientos sean seguros y eficaces ${ }^{[22]}$. Así mismo, la posible falta de plan de monitoreo, especialmente de información sobre efectos adversos (22\%) y la ausencia de consentimiento informado en algunos casos (15\%) es inadmisible desde el punto de vista bioético ${ }^{[23]}$.

Un aspecto preocupante es que los resultados nos hacen pensar que la colaboración entre los investigadores para favorecer el 
beneficio social sería muy pequeña o nula, puesto que el $30 \%$ opina así.

Cabe señalar las limitaciones de la investigación. El cuestionario es largo: 57 preguntas. Esto va unido a la poca disponibilidad de tiempo por parte de los médicos, que deben atender emergencias, pasar visita, consultas, entre otras. Adicionalmente, solo un médico que trabaja en clínicas que ofertan terapias con células madres llenó el cuestionario. No obstante, si hubiéramos entrevistado sólo a médicos de especialidades relacionadas con estas terapias celulares, que tienen un mayor conocimiento de estos asuntos y debieran llamar la atención sobre la necesidad de trabajar sólo con los procedimientos seguros y comprobados, tal vez podríamos haber obtenido unos resultados más desfavorables a la realización de algunas de estas terapias; sin embargo, posibles conflictos de interés podrían sesgar las respuestas. Por ese motivo preferimos acudir a médicos generales y de todas las especialidades ${ }^{[24]}$

Por otro lado, como recomendaciones, planteamos que tanto las Universidades como los Colegios Médicos latinoamericanos y, en el Perú, la Asociación Peruana de Facultades de Medicina (ASPEFAM, ver: http://www.aspefam.org.pe/) debieran plantearse mejorar la formación de los médicos en estos aspectos pues el cuestionario arroja un dato importante: hay alrededor de un $30 \%$ de desconocimiento acerca de la aplicación de terapias con células madre. Los diferentes niveles de gobierno de los distintos países de Latinoamérica deberían fiscalizar estas clínicas para asegurar que cumplan la normativa establecida. Así mismo, los poderes legislativos tendrían que aprobar nuevas leyes sobre terapias de avanzada y poner al día las que existen actualmente. En dichas leyes se debería contemplar la compensación por daños provenientes de esos tratamientos, así como la exigencia de una actuación impecable desde el punto de vista científico y bioético. Por otra parte, conviene difundir a nivel general las recomendaciones dadas en el Manual del Paciente sobre Terapias con Células Madre por la ISSCR ${ }^{[25]}$ para que las personas aquejadas de alguna patología susceptible de ser tratada mediante estas terapias, conozcan acerca de la seguridad y eficacia de esos tratamientos. Finalmente, los propios profesionales de la medicina, apoyados en los colegios médicos, deberían plantearse revalorar la esencia del acto médico que conlleva priorizar el beneficio real del paciente por encima de avances científicos reales, potenciales o supuestos y, sobre todo, del éxito profesional o económico ${ }^{[26]}$.

Se puede concluir que, en opinión de una muestra de médicos peruanos, en Latinoamérica se estaría ofertando terapias con células madre para tratar enfermedades muy diversas, entre las que destacan las neurodegenerativas que, como sabemos, en la actualidad son incurables y los posibles tratamientos están a nivel de ensayos clínicos. Por tanto, no sería ético hacerlo por tratarse de procedimientos no experimentados ni aprobados. En definitiva, no se estarían tomando todas las providencias necesarias para que el procedimiento se pueda calificar como científica y bioéticamente aceptable.
Agradecimiento: al Dr. César Gutiérrez Villafuerte por su colaboración en la presentación de este artículo, de forma especial tablas y gráficos.

Fuente de financiamiento: autofinanciado.

Conflictos de interés: El autor declara no tener conflictos de interés.

\section{REFERENCIAS BIBLIOGRÁFICAS}

1. Millás J. Las células madre y la medicina regenerativa. De las células madre embrionarias a la reprogramación celular. Therapeía. 2010;(2):13-27.

2. Gratwohl A, Baldomero H, Passweg J. Hematopoietic stem cell transplantation activity in Europe. Curr Opin Hematol. 2013;20(6):485-93.

3. Bargues L, Prat M, Leclerc T, Bey E, Lataillade JJ. [Present and future of cell therapy in burns].

Pathol Biol (Paris). 2011;59:e49-56. [Article in French]

4. Brittberg M. Cell carriers as the next generation of cell therapy for cartilage repair: a review of the matrix-induced autologous chondrocyte implantation procedure. Am J Sports Med. 2010;38(6):1259-71.

5. Rama P, Matuska S, Paganoni G, Spinelli A, De Luca M, Pellegrini G. Limbal stem-cell therapy and long-term corneal regeneration. N Engl J Med. 2010;363(2):147-55.

6. Zheng GP, Ge MH, Shu Q, Rojas M, Xu J. Mesenchymal stem cells in the treatment of pediatric diseases. World J Pediatr. 2013;9(3):197-211.

7. Schmidt C. FDA approves first cell therapy for wrinkle-free visage. Nat Biotechnol. 2011;29(8):674-5.

8. Di Lorenzo G, Ferro M, Buonerba C. Sipuleucel-T (Provenge ${ }^{\circledR}$ ) for castration-resistant prostate cancer. BJU Int. 2012;110 (2 Pt 2):E99-104.

9. Collins LR, Priest C, Caras I, Littman N, Kadyk L. Proceedings: moving toward cell-based therapies for heart disease. Stem Cells Transl Med. 2015;4(8):863-7.

10. Garcia-Olmo D, Schwartz DA. Cumulative evidence that mesenchymal stem cells promote healing of perianal fistulas of patients with Crohn's disease-going from bench to bedside. Gastroenterology. 2015;149(4):853-7.

11. Lunn JS, Sakowski SA, Feldman EL. Concise review: stem cell therapies for amyotrophic lateral sclerosis: recent advances and prospects for the future. Stem Cells. 2014;32(5):1099-109.

12. Li MD, Atkins H, Bubela T. The global landscape of stem cell clinical trials. Regen Med. 2014;9(1):27-39.

13. Dubnicoff T. Desperate patients and false hope: a troubling trend for stem cell-based therapies. 2015 Jun 4 [citado el 5 de junio de 2015]. In: The Stem Cellar: The Official Blog of CIRM, California's Stem Cell Agency [Internet]. San Francisco, USA: CIRM; c2015. Disponible en: http://blog.cirm.ca.gov/2015/06/04/desperate-patients-and-falsehope-a-troubling-trend-for-stem-cell-based-therapies/

14. StemGenex Medical Group [Internet]. La Jolla, CA; StemGenex; c2017. [citado el 5 de junio de 2015]. Disponible en: https:// stemgenex.com/

15. U.S. National Institutes of Health [Internet]. Rockville Pike, Bethesda, Maryland; NIH; c2015 [citado el 5 de junio de 2015]. Disponible en: www.clinicaltrials.gov

16. International Society for Stem Cell Research. Guidelines for the Clinical Translation of Stem Cells [Internet]. Skokie, Illinois: ISSCR; c2016 [citado el 15 de mayo de 2016]. Disponible en: www.isscr. org

17. Gastens MH, Goltry K, Prohaska W, Tschöpe D, Stratmann B, Lammers $D$, et al. Good manufacturing practice-compliant 
expansion of marrow-derived stem and progenitor cells for cell therapy. Cell Transplant. 2007;16(7):685-96.

18. Liu X, Fang Q, Kim H. Preclinical studies of mesenchymal stem cell (MSC) administration in chronic obstructive pulmonary disease (COPD): A systematic review and meta-analysis. PLoS One. 2016;11(6):e0157099.

19. Tomasetti C, Li L, Vogelstein B. Stem cell divisions, somatic mutations, cancer etiology, and cancer prevention. Science. 2017;355(6331):1330-4.

20. Hyun I. Allowing innovative stem cell-based therapies outside of clinical trials: ethical and policy challenges. J Law Med Ethics. 2010;38(2):277-85.

21. Elsawy M, Sorror ML. Up-to-date tools for risk assessment before allogeneic hematopoietic cell transplantation. Bone Marrow Transplant. 2016;51(10):1283-300.

22. Master Z, Caulfield T. Patient booklet: What you need to know about stem cell therapies [Inernet]. Edmonton, Alberta: Health Law Institute/Stem Cell Network/Albany Medical College; 2014 [citado el 7 de julio de 2016]. Disponible en: http://www.hli.ualberta.ca/ en/Completed\%20Research/ /media/hli/Research/Docs/201402_SC_Patient_Booklet.pdf

23. Raina V. Investigators viewpoint on ethics, methods, and informed consent in clinical trials. Perspect Clin Res. 2013;4(1):39-40.

24. Salas SP. Conflicto de intereses en la investigación biomédica. Rev Chil Obstet Ginecol. 2010;75(3):143-5.

25. International Society for Stem Cell Research. Manual del paciente sobre terapias con células madre. Apéndice de la Guía para la Traslación Clínica de las Células Madre [Internet]. Deerfield, Illinois: ISSCR; 2008 [citado el 26 de marzo de 2016]. Disponible en: http://www.closerlookatstemcells.org/docs/default-source/ patient-resources/patient-handbook---spanish.pdf

26. ABIM Foundation. American Board of Internal Medicine; ACP-ASIM Foundation. American College of Physicians-American Society of Internal Medicine; European Federation of Internal Medicine. Medical professionalism in the new millennium: a physician charter Ann Intern Med. 2002;136(3):243-6.

\title{
Las ediciones anteriores de Acta Médica Peruana están disponibles en:
}

\author{
www.redalyc.org
}

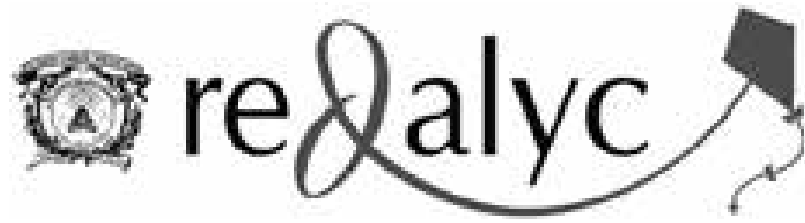

